\title{
Effect of Grazing Flow on Grooved Over-the-Rotor Acoustic Casing Treatments
}

\author{
Richard F. Bozak* \\ NASA Glenn Research Center, Cleveland, Ohio, 44135, USA \\ Michael G. Jones ${ }^{\dagger}$, Brian M. Howerton ${ }^{\ddagger}$, and Martha C. Brown ${ }^{\S}$ \\ NASA Langley Research Center, Hampton, Virginia, 23681, USA
}

\begin{abstract}
After testing grooved over-the-rotor acoustic casing treatments on a turbofan rotor, a follow-on study was performed to investigate the effect of flow on grooved acoustic liners. The experiment was performed to understand the scaling of acoustic liner absorption with grazing flow and investigate a potential noise source from grooved acoustic liners. Acoustic liner absorption and reflection characteristics were quantified by examining the reduction in amplitude of a plane wave traveling over 2 inch liners with grazing flow. For all liners tested, as the grazing flow Mach number is increased, the absorption curves broadened and the frequency of peak absorption decreased. Grazing flow over a series of grooves was found to generate resonances up to $152 \mathrm{~dB}$ sound pressure level. Adding acoustic treatment to the bottom of these grooves was found to reduce the magnitude of this resonance by up to $10 \mathrm{~dB}$ sound pressure level and increase its frequency by up to $10 \%$. The quantification of the grazing flow effect and identification of a mechanism behind the noise penalty from the prior turbofan rotor experiment will aid in the design of future over-the-rotor treatments.
\end{abstract}

\section{Nomenclature}

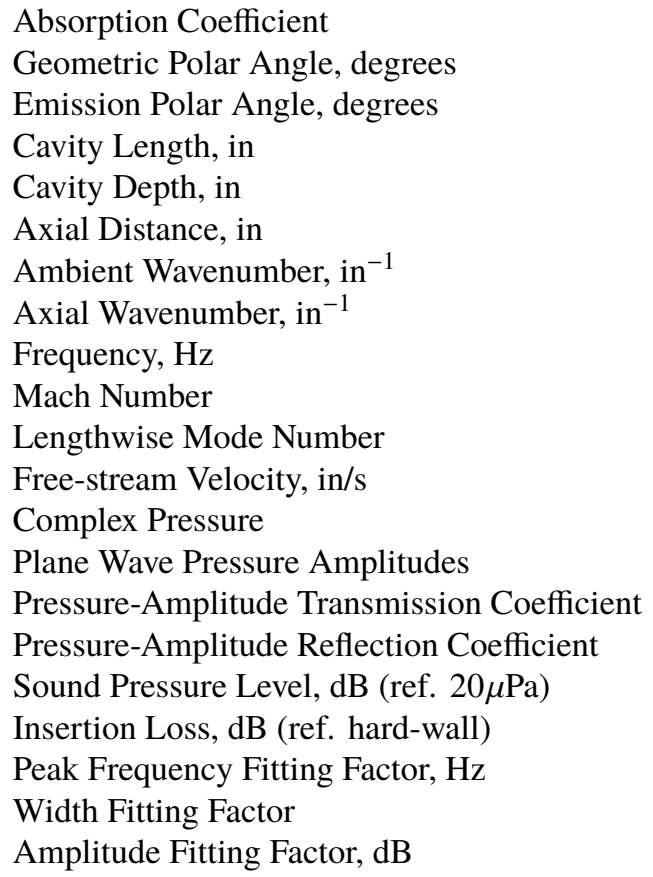

\footnotetext{
*Research Aerospace Engineer, Acoustics Branch, AIAA Member.

${ }^{\dagger}$ Senior Research Scientist, Structural Acoustics Branch, AIAA Associate Fellow.

$¥$ Research Scientist, Structural Acoustics Branch, AIAA Senior Member.

${ }^{\S}$ Research Engineer, Aeroacoustics Branch, AIAA Member.
} 


$\begin{array}{ll}\text { Subscripts } & \\ u & \text { Upstream, relative to the flow direction } \\ d & \text { Downstream, relative to the flow direction } \\ h w & \text { Hard-wall Configuration } \\ L & \text { Lengthwise Mode } \\ D & \text { Depthwise Mode }\end{array}$

\section{Introduction}

NASA's aeronautics projects have been developing aircraft engine noise reduction technologies for a number of years. Fan noise is expected to remain a large contributor to airport noise for advanced subsonic transport aircraft [1]. Over-the-rotor acoustic liners have been shown to reduce sound power level by as much as 4-5 dB [2], but have also shown significant aerodynamic performance losses [3]. Ultra-high bypass ratio turbofan engines have reduced the area available for inlet liners, so over-the-rotor liners present an opportunity to further reduce fan noise.

NASA has been developing over-the-rotor acoustic treatments for a number of years. The latest iterations of over-the-rotor acoustic treatments have incorporated circumferentially grooved fan cases [2, 4, 5] to mitigate the issues [6] found when subjecting an acoustic treatment to large dynamic pressure fluctuations. The combination of a fan casing treatment with an acoustic liner led to the desire to isolate the circumferential groove effects from the acoustic liner effects. Therefore, a series of tests were devised to investigate the impacts of circumferential grooves and acoustic liners on fan aerodynamic performance and noise.

These tests were performed at various Technology Readiness Levels (TRLs) to further understand the effects of acoustic liners in the over-the-rotor environment. First, Normal Incidence Tube (NIT) testing was performed in 2015 to quantify the no-flow impedance of each liner. Then, testing was conducted on the Advanced Noise Control Fan (ANCF) [7] to quantify the treatment impact on a low speed fan. Finally, the treatments were tested in the W-8 Single Stage Compressor Facility (W-8) [5, 8] installed over a high bypass, turbofan rotor. In order to isolate the circumferential groove effect from the acoustic liner effect, testing in all facilities included hard-wall and grooved baseline configurations. The results from the turbofan rotor test in W-8 showed treatment noise reduction from 2-3 dB inlet in-duct sound power level (PWL). The peak frequency of this reduction decreased as the fan speed increased. Additionally, a 6-8 dB noise penalty was measured from $4-8 \mathrm{kHz}$ at lower fan speeds due to the inclusion of circumferential grooves. This penalty was reduced when acoustic treatments were incorporated into the bottom of the circumferential grooves.

The findings from the turbofan rotor test in W-8 led to interest in investigating the effect of grazing flow Mach number on the frequency of peak noise reduction, as well as the possible causes of additional high frequency $(4-8 \mathrm{kHz})$ noise due to the inclusion of circumferential grooves over the rotor. Therefore, an experiment was conducted in the Grazing Flow Impedance Tube (GFIT) at NASA Langley Research Center [9] to further investigate these effects. The GFIT test was designed to utilize existing 2 inch liner samples of the same treatments tested over-the-rotor. The experiment had two primary objectives; determine the scaling of over-the-rotor acoustic liner characteristics with grazing flow Mach number and determine if the noise increase measured in W-8 is due to axial flow over grooves.

While all testing described was conducted in the GFIT, the experiment and results for each objective are presented separately. First, details of the facility and hardware are presented. Then, the measurements and results from the liner scaling experiment are presented along with an empirical model fit to the insertion loss results. Finally, results from the groove noise investigation are presented and discussed.

\section{Experiment}

\section{A. Grazing Flow Impedance Tube (GFIT)}

The test was conducted in the Grazing Flow Impedance Tube (GFIT) at NASA Langley Research Center [9]. The GFIT facility is used to determine the acoustic characteristics of liners in the presence of grazing flow up to Mach 0.6. Source levels up to $150 \mathrm{~dB}$ SPL can be generated at either end of the test section at frequencies between $400 \mathrm{and} 3000 \mathrm{~Hz}$. For the testing described, the facility was operated in inlet mode where the noise was generated downstream resulting in flow and sound traveling in opposite directions as shown in Fig. 11 The liners tested were a set originally fabricated for use in the Normal Incidence Tube (NIT) at NASA Langley Research Center, and are therefore only 2 inches in length. The 2 inch liners were inserted into the center of the test section with flow normal to the grooves, as shown in Figs. 1 . and2. An array of 95 flush-mounted microphones line the center portion of the GFIT duct. Data acquired from these 
microphones are typically utilized to educe liner impedance. For both the liner scaling and cavity noise experiments, subsets of these microphones were examined to determine the groove and liner effects.

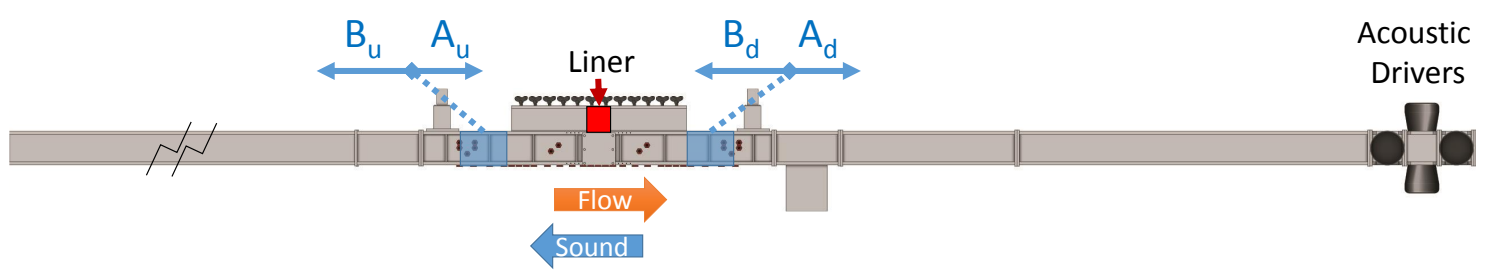

Fig. 1 Schematic of the Grazing Flow Impedance Tube (GFIT) at NASA Langley Research Center shown as used for Over-the-Rotor Liner testing in inlet mode (flow and sound traveling in opposite directions).

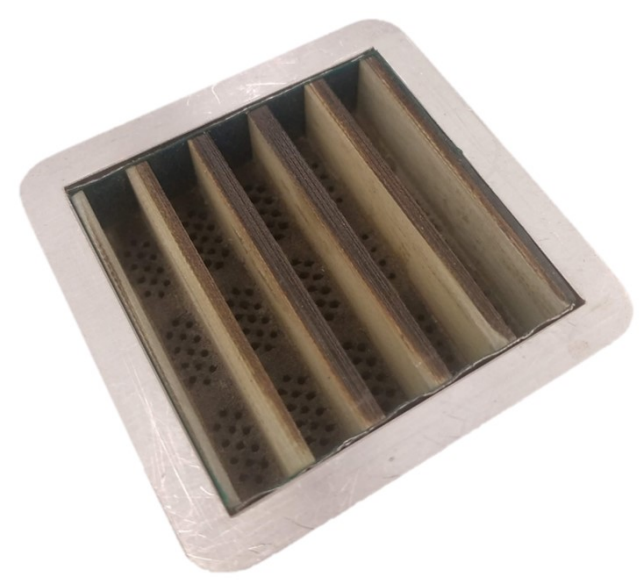

Fig. 2 A 2 inch by 2 inch over-the-rotor acoustic casing treatment sample.

\section{B. Treatment Configurations}

A total of six configurations were tested in GFIT, matching those that were tested in the ANCF [7] and in W-8 [5]. Two baseline fan cases and four treated configurations were used to isolate the circumferential groove effects from the acoustic treatment effects as depicted in Fig. 3. The first configuration was a hard-wall baseline fan case. The second configuration consisted of a series of grooves to represent the circumferential grooves tested over-the-rotor [5, 7]. While sound absorption from this configuration was not expected, it allowed for separation of the impact of the grooves from the treatment effects. All configurations consisted of sheets of Garolite G10 cut to size and layered axially to create a liner. Five rows of grooves extend about 2 inches in the axial direction. Each groove is $1 / 2$ inch deep and $1 / 4$ inch wide with $1 / 8$ inch wide ribs between adjacent grooves, as shown in the center of Fig. 3 In the bottom of the grooves, the four treated fan case configurations had 0.035 inch diameter perforate holes with $10 \%$ open area leading to various acoustic treatments. The four treated configurations, shown in Fig. 4. consisted of one with 0.06 inch perforate depth and empty 1 inch deep chambers (a), one with a $1 / 4$ inch perforate depth and 1 inch deep empty chamber (b), one matching the empty chamber geometry with 80ppi 8\% FeCrAlY metal foam in the chambers (c), and one with fins in the chambers to provide expansion of high amplitude pressure waves (d).

\section{Groove Configurations}

In order to investigate the noise generated from flow over a series of 5 grooves/cavities, the baseline groove sample was modified as shown in Fig. 5. By filling some of the grooves, a subset of exposed grooves could be tested. A binary name is used to define which of the five grooves are exposed; where "00100" denotes only the middle grooves exposed, "11111" denotes all grooves exposed, and therefore, "00000" would be the equivalent of a hard-wall. 


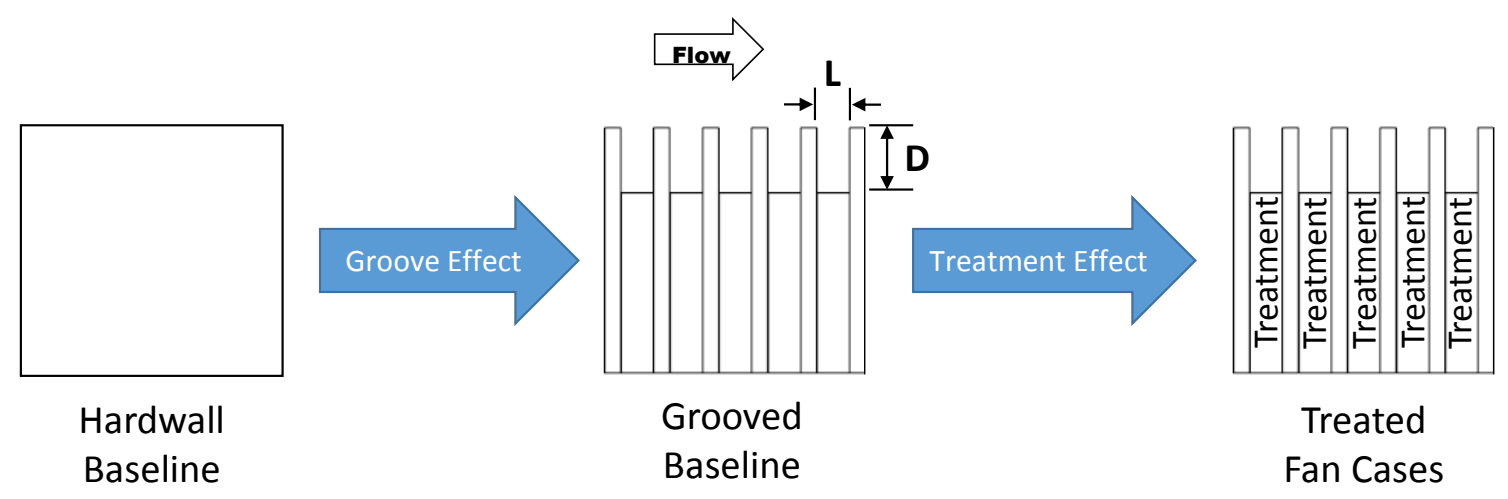

Fig. 3 Cross-sections of fan case configurations for determining groove and treatment effects.

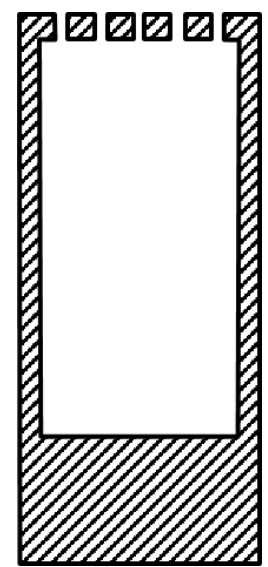

(a)

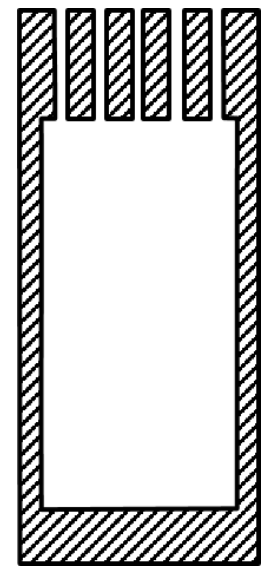

(b)

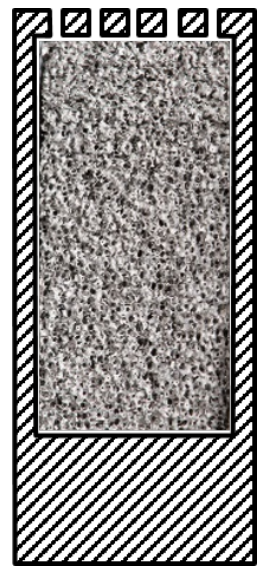

(c)

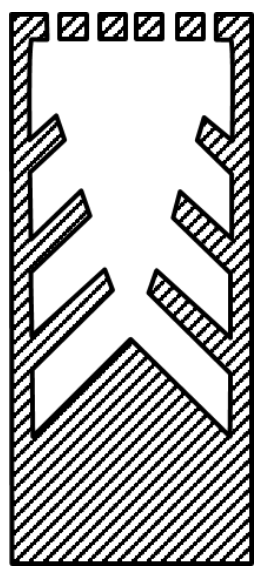

(d)

Fig. 4 Cross-sections of the acoustic treatments (flow direction is into the page), (a) Empty Chamber Treatment, (b) Thick Perforate Treatment, (c) Foam Metal Treatment, and (d) Expansion Chamber Treatment.

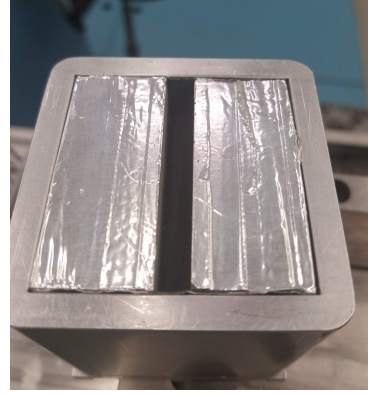

(a) 00100

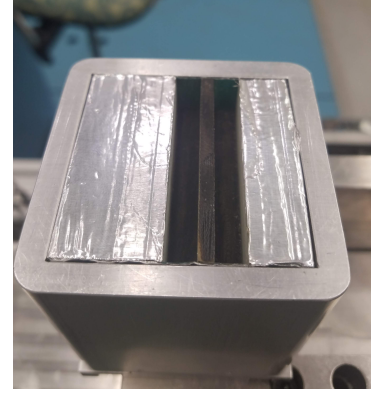

(b) 00110

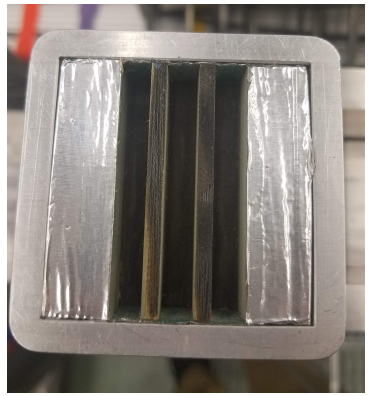

(c) 01110

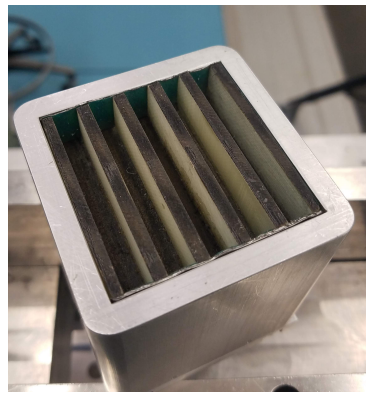

(d) 11111

Fig. 5 Groove configurations used for the cavity noise investigation. 


\section{Liner Scaling with Grazing Flow}

\section{A. Analysis}

Liner performance is evaluated by comparing the sound levels between the liner configurations and the hard-wall baseline. The GFIT generates a plane wave that travels down the duct [9]. Impedance discontinuities in the duct can reflect sound back towards the acoustic drivers. Therefore, the complex pressure, $p$, at any location in the duct is the sum of forward and backward propagating plane waves, as shown in Eq. 1. where the axial wavenumber is given in Eq. 2. Backward propagating plane waves travel with the flow and are denoted by $A$, while forward propagating plane waves travel against the flow and are denoted by $B$ as shown in Fig. 1

$$
\begin{gathered}
p=A e^{i\left(\omega t-k_{x} x\right)}+B e^{i\left(\omega t+i k_{x} x\right)} \\
k_{x}=\frac{k_{o}}{1 \pm M}
\end{gathered}
$$

For any two locations, the magnitude of the complex pressure in each direction can be solved via Eq. 3

$$
\left[\begin{array}{l}
p_{1} \\
p_{2}
\end{array}\right]=\left[\begin{array}{ll}
e^{-i k_{x} x_{1}} & e^{i k_{x} x_{1}} \\
e^{-i k_{x} x_{2}} & e^{i k_{x} x_{2}}
\end{array}\right]\left[\begin{array}{l}
A e^{i \omega t} \\
B e^{i \omega t}
\end{array}\right]
$$

The forward and backward plane wave amplitudes were calculated for each the upstream $(u)$ and downstream $(d)$ ends of the GFIT duct. These quantities on either side of the liner can then be used to calculate a pressure-amplitude transmission coefficient $(T)$, a pressure-amplitude reflection coefficient $(R)$, and an absorption coefficient $(\alpha)$ as shown in Eqs. 4]6[10].

$$
\begin{gathered}
T=\frac{B_{u}}{B_{d}} \\
R=\frac{A_{d}-A_{u}}{B_{d}} \\
\alpha=1-T^{2}-R^{2}
\end{gathered}
$$

In order to evaluate scaling effects of liner concepts, the insertion loss for each treatment is calculated relative to the hard-wall baseline $\left(T_{h w}\right)$, as shown in Eq. 7. The insertion loss includes losses due to both liner absorption and reflection.

$$
I L=-20 \log \left(\frac{T}{T_{h w}}\right)
$$

\section{B. Experiment Summary}

The liner scaling experiment was conducted with the GFIT operating in inlet mode with the grazing flow and sound traveling in opposite directions. For grazing flow Mach numbers from 0 to 0.5 in 0.1 Mach increments, acoustic drivers generated primarily a plane wave at each frequency from 400 to $3000 \mathrm{~Hz}$ in $100 \mathrm{~Hz}$ increments. The baseline hard-wall and baseline grooved liners were tested along with the 4 liner concepts shown in Fig. 4 . On either end of the GFIT duct, data from a series of seven microphones spanning 4 inches axially on the bottom of the duct measured the complex pressure at each condition. The microphones were located 11 inches from either end of the liner to avoid near field effects. These measurements were utilized with a least-squares fit to solve Eq. 3.

\section{Results}

For each Mach number and frequency tested, the transmission coefficient, reflection coefficient, and absorption coefficient were calculated to determine the effect of grazing flow Mach number on the performance of the over-the-rotor acoustic liners. Fig. 6 shows the impact of increasing grazing flow on the absorption coefficient for each of the six configurations. The absorption coefficient for the hard-wall configuration shows the GFIT duct losses increase with increasing flow speed. The grooved baseline configuration shows elevated absorption at higher frequencies relative 
to the hard-wall baseline. At Mach 0.5 and frequencies above $2200 \mathrm{~Hz}$, the erratic behavior of the grooved baseline absorption suggests that a higher order mode may be cut on. The grooved configuration has a larger cross-sectional area which may allow for a cut on mode in addition to the plane wave mode. For the four treated configurations Fig. 6(c-f), as the grazing Mach number increases, the liner absorption increases and the frequency of the peak absorption decreases. The absorption curves also broaden (increase in width) as the grazing flow Mach number increases.

The reflection coefficient for each configuration is shown in Fig. 7. As expected, the hard-wall configuration does not show reflective behavior since there is no impedance discontinuity. While the grooves provide a potential impedance discontinuity, reflections were not measured over this frequency range. The reflective behavior of the four treated configurations consists of a reflection that coincides with the frequencies of peak attenuation. The magnitudes of the reflections decrease as the grazing flow Mach number is increased. A negative reflection coefficient signifies a condition where the GFIT duct's upstream termination reflection is larger than the treatment reflection.

The insertion loss includes both the effects of absorption and reflection to show the total noise reduction of these liners on an inlet observer. The insertion loss relative to the hard-wall baseline also removes the effect of the GFIT duct losses. Fig. 8 shows the measured insertion loss for each liner configuration. The grooved baseline configuration shows slightly elevated insertion loss at higher Mach numbers and frequencies with the higher order mode contamination evident above $2200 \mathrm{~Hz}$. For the four liner configurations, as grazing flow Mach number increases the insertion loss curves broaden and the frequency of peak insertion loss decreases. The empty and expansion chamber treatments, Fig. 8 (c,f), show a decrease in the amplitude of peak insertion loss as Mach number increases, due to the decreasing reflection coefficient. Otherwise, the insertion loss curves are consistent with the absorption curves. While only 2 inch long liner samples were tested, insertion losses over $10 \mathrm{~dB}$ represent a significant reduction in sound level.

\section{Empirical Fit Scaling}

In an effort to extract the major effects of grazing flow on the acoustic treatments a polynomial is fit to each of the insertion loss curves from Fig. 8. A second order polynomial was chosen to simplify the curve into a width factor, $w_{f}$, peak frequency factor, $p_{f}$, and an amplitude factor, $a_{f}$, as shown below in Eq. 8. A least-squares fit is applied to the data which ignores insertion losses below $2.5 \mathrm{~dB}$. This fit was applied for each treatment configuration at each Mach number. A sample curve fit is shown in Fig. 9

$$
I L=-\frac{\left(f-p_{f}\right)^{2}}{w_{f}}+a_{f}
$$

The effect of Mach number on these curve-fits is evaluated by examining the width, peak frequency, and amplitude factors over the range of grazing flow Mach numbers from 0 to 0.5. The effect of Mach number on each of these factors is shown in Fig. 10 The increasing trend of the effect of Mach number on the width factor $\left(w_{f}\right)$, Fig. 10 (a), quantifies the broadening of the noise reduction curve as flow Mach number is increased. The foam metal treatment is offset from the others because it exhibited a broader noise reduction curve even without flow. The effect of Mach number on the peak frequency factor $\left(p_{f}\right)$, Fig. 10 (b), shows a reduction in peak frequency as Mach number increases, with a similar slope for all treatments. The effect of Mach number on the amplitude factor $\left(a_{f}\right)$, Fig. 10 (c), shows a reduction in the peak insertion loss as grazing flow Mach number is increased for the empty and expansion chamber concepts, which was noted to be due to a decreasing reflection coefficient. However, the peak absorption coefficient tends to increase with increasing grazing flow Mach number.

The curve fit factors in Fig. 10 are useful for correlating no flow impedance tube measurements with data from a liner installed in a turbofan engine. These factors may be used in a design process to define frequency of peak insertion loss at an expected Mach number and determine the target peak frequency for no flow peak impedance measurements. Since the treatment effectiveness is a combination of the width factor and amplitude factor, the sensitivity of these to grazing flow Mach number can then be used to estimate the expected insertion loss from no flow Normal Incidence Tube measurements. 


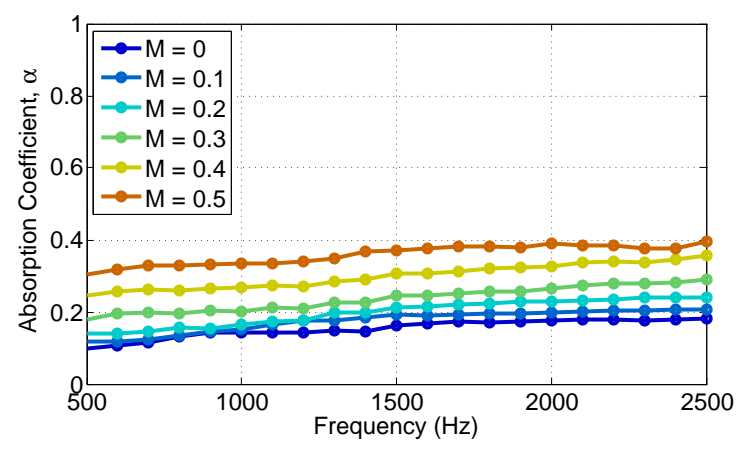

(a) Hard-wall Baseline

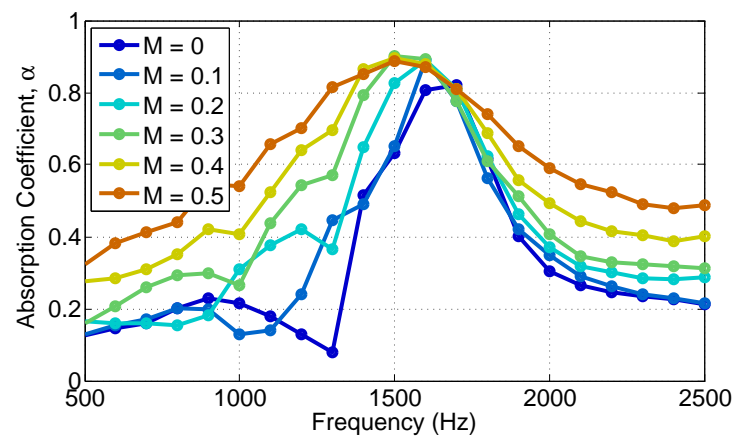

(c) Empty Chamber Treatment

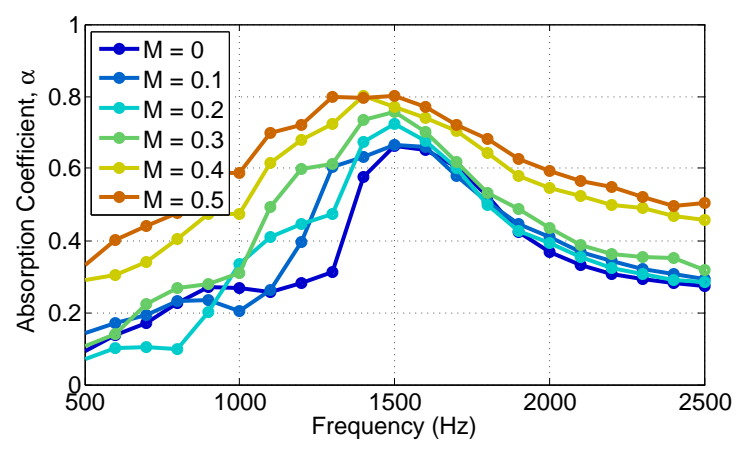

(e) Foam Metal Treatment

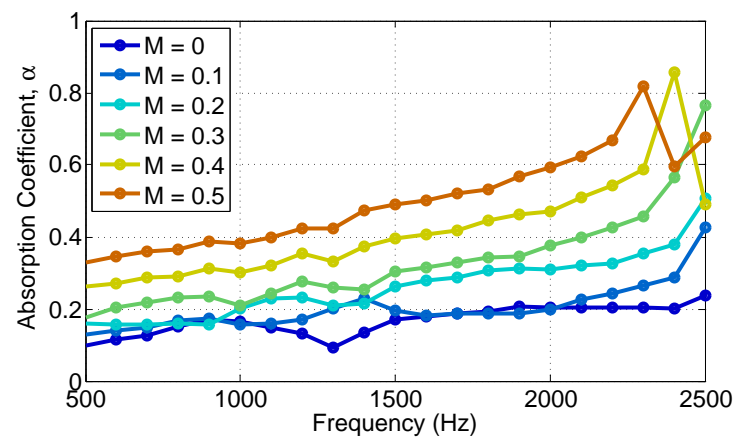

(b) Grooved Baseline

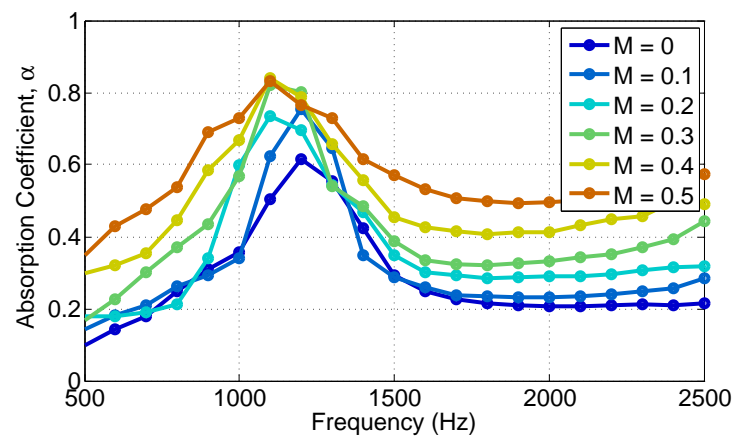

(d) Thick Perforate Treatment

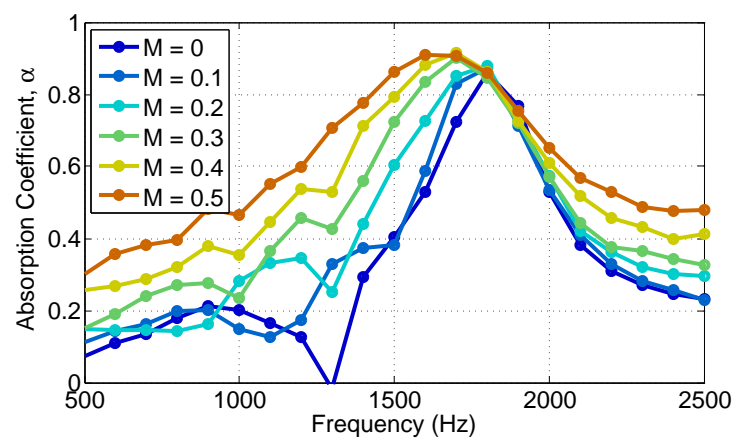

(f) Expansion Chamber Treatment

Fig. 6 Absorption coefficient with increasing grazing Mach number for each configuration. 


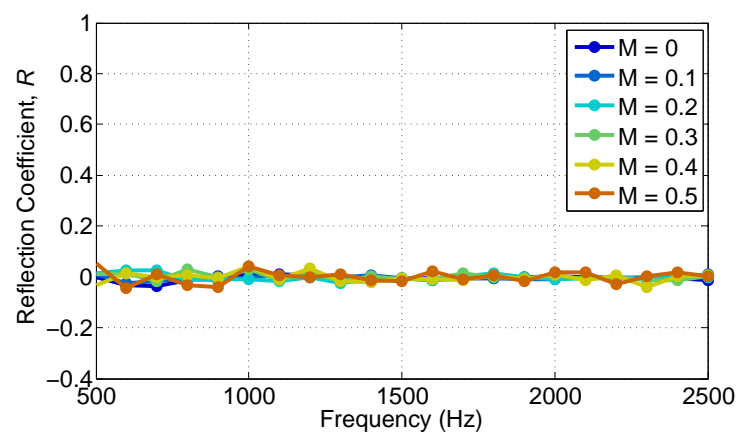

(a) Hard-wall Baseline

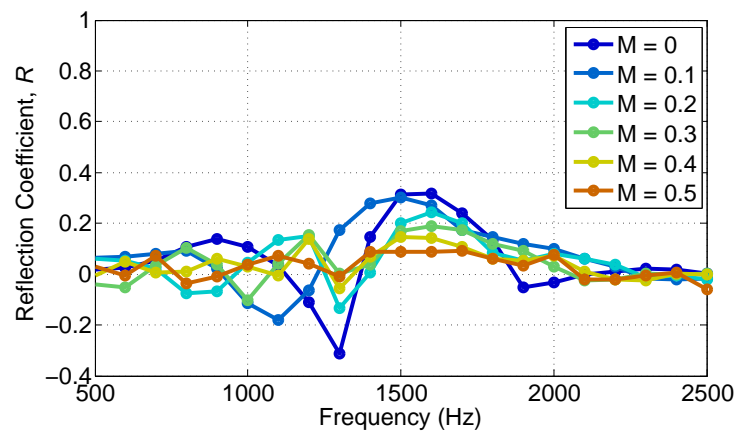

(c) Empty Chamber Treatment

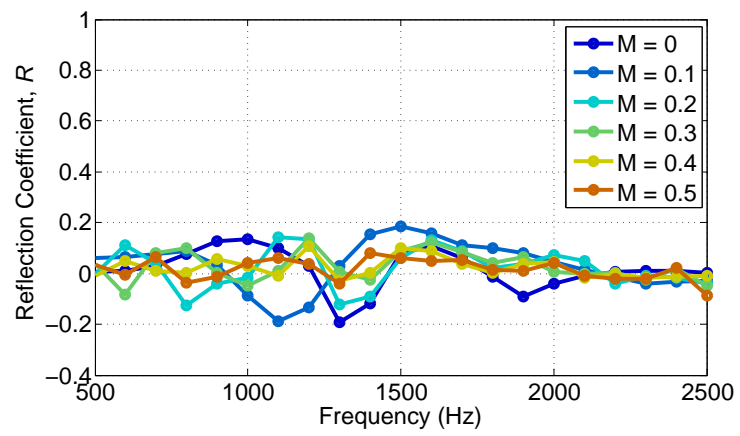

(e) Foam Metal Treatment

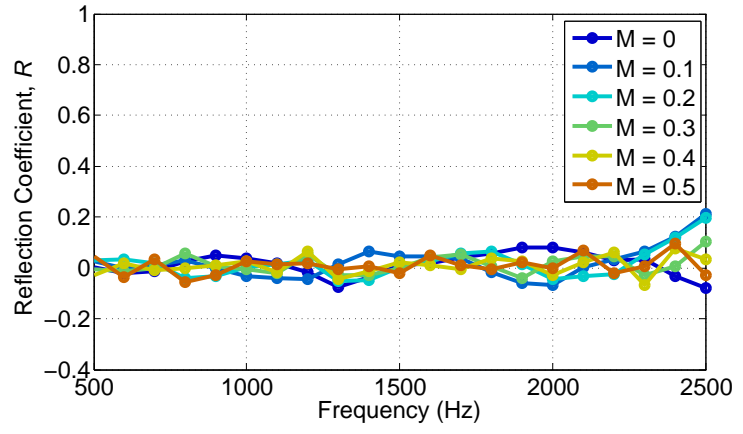

(b) Grooved Baseline

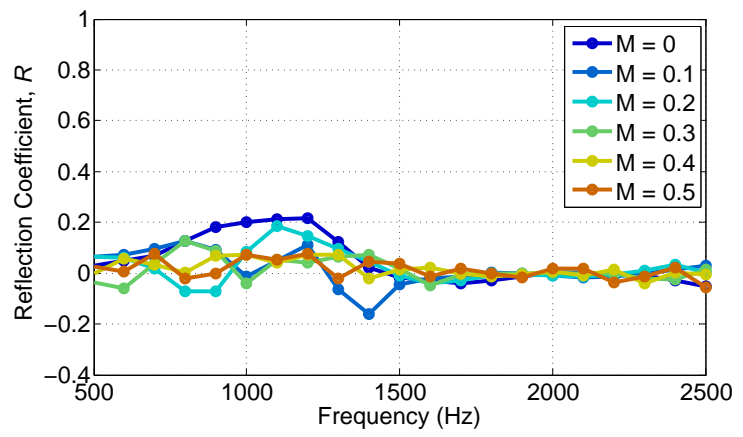

(d) Thick Perforate Treatment

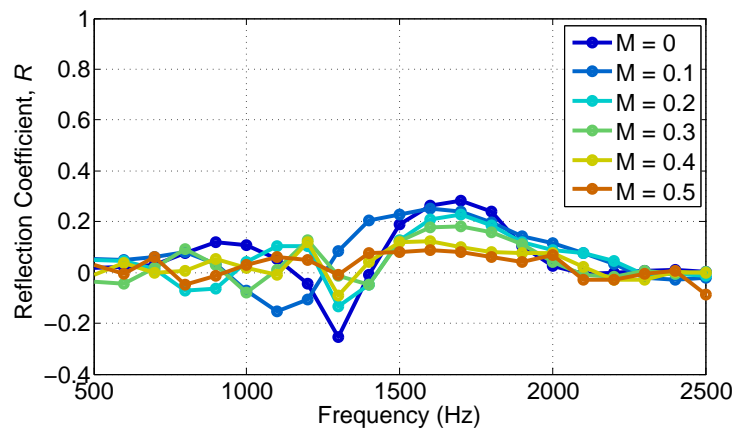

(f) Expansion Chamber Treatment

Fig. 7 Reflection coefficient with increasing grazing Mach number for each configuration. 


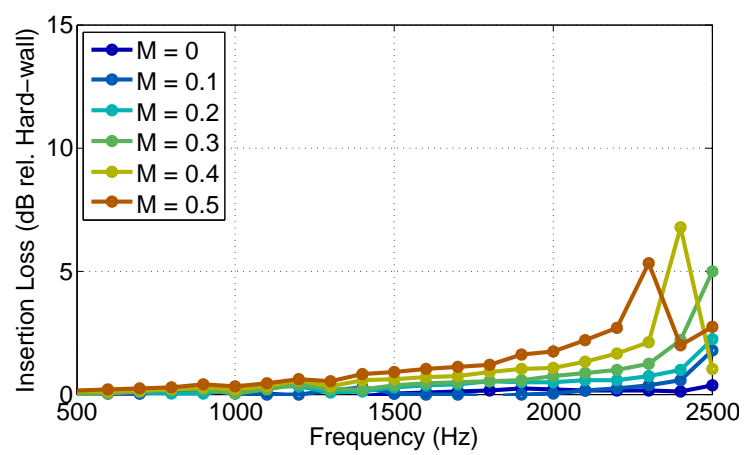

(b) Grooved Baseline
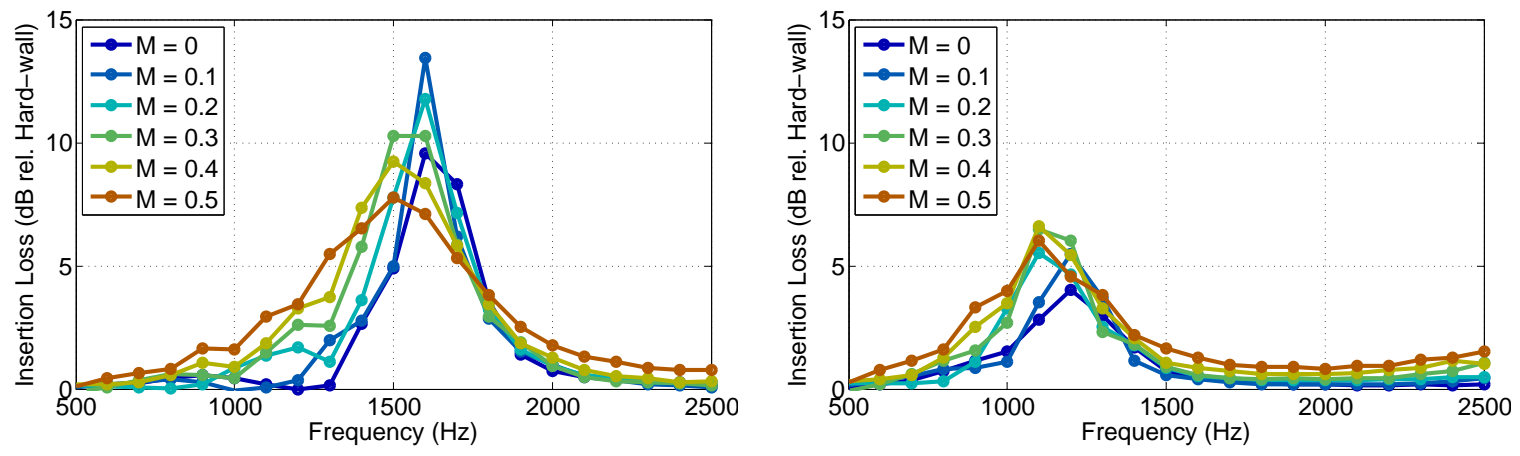

(c) Empty Chamber Treatment

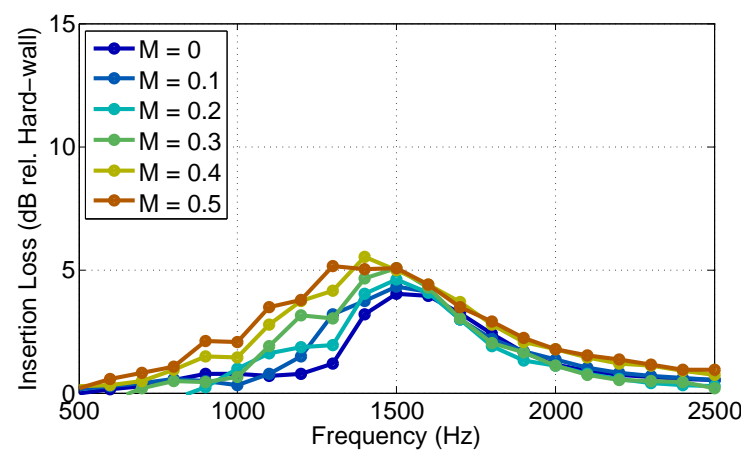

(e) Foam Metal Treatment

(d) Thick Perforate Treatment

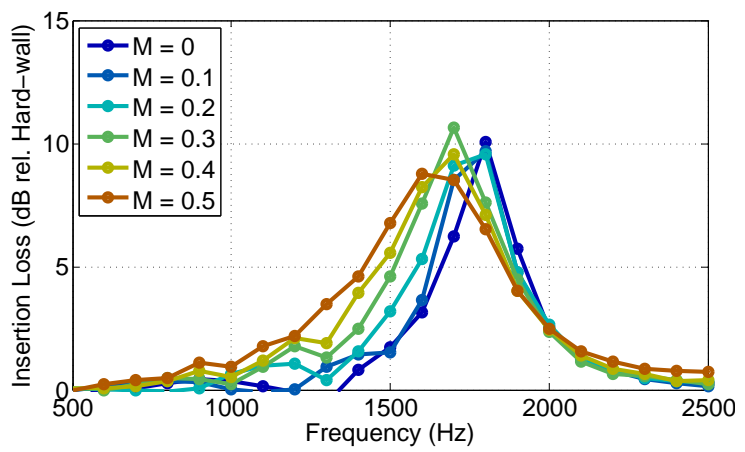

(f) Expansion Chamber Treatment

Fig. 8 Insertion loss relative to hard-wall with increasing grazing Mach number for each configuration. 


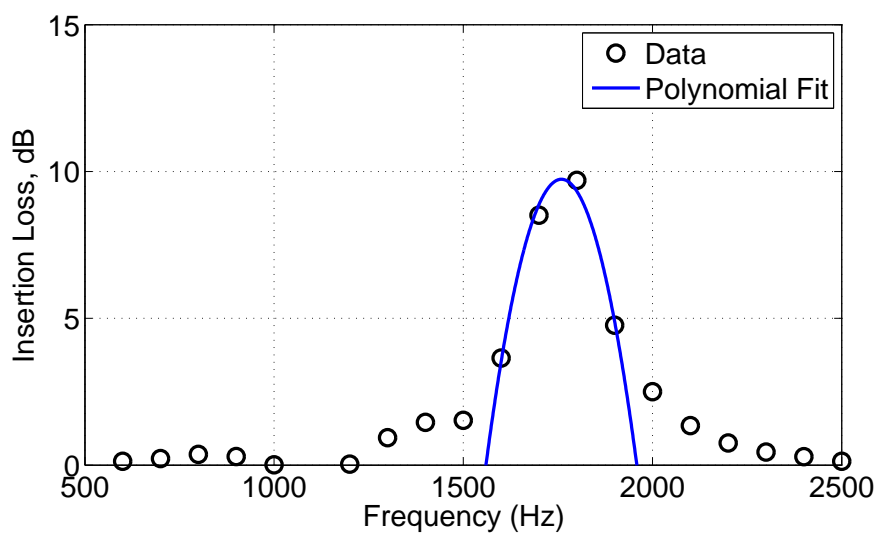

Fig. 9 Sample polynomial fit to insertion loss data for the Expansion Chamber Treatment at Mach 0.1.

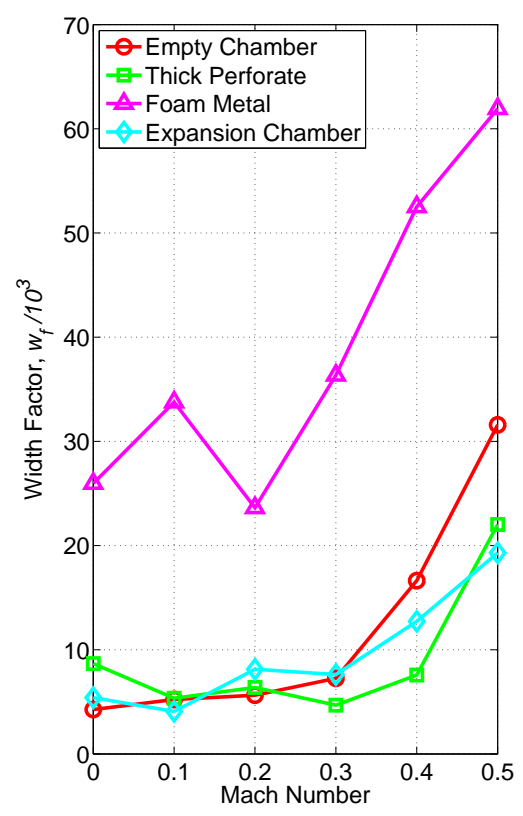

(a) Width Factor, $w_{f}$

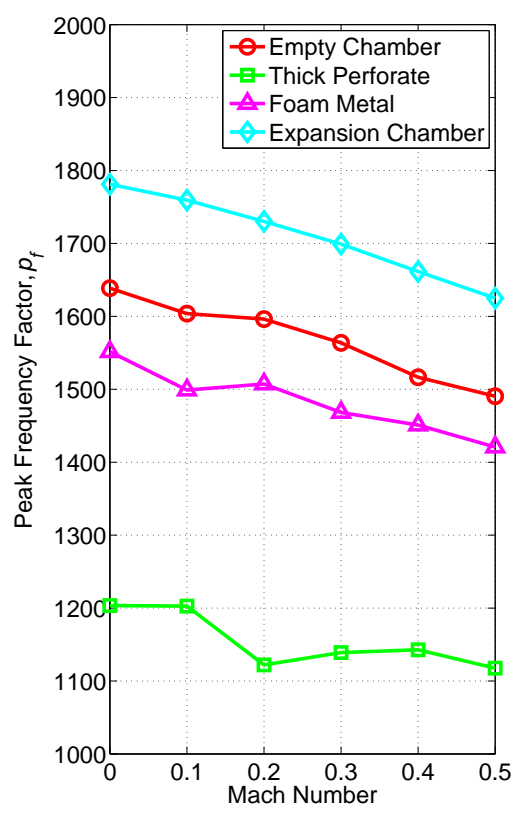

(b) Peak Frequency Factor, $p_{f}$

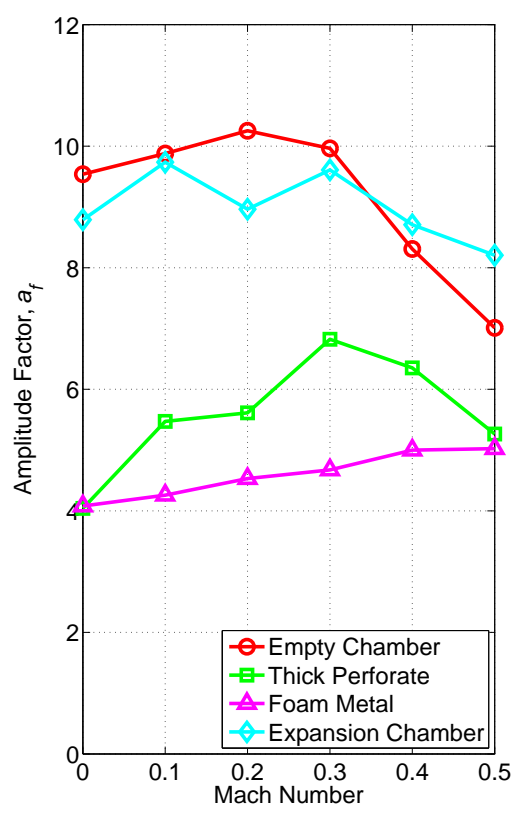

(c) Amplitude Factor, $a_{f}$

Fig. 10 Effect of grazing flow Mach number on polynomial fit factors from Eq. 8 for each liner configuration. 


\section{Cavity Noise Investigation}

Testing of acoustic casing treatments over a turbofan rotor showed that at low fan speeds ( $<61.7 \%$ design speed) the circumferential grooves created an additional 5-7 dB in-duct sound power level between 4 and $8 \mathrm{kHz}$ [5]. One possible source of this could be noise generated from axial flow over the circumferential grooves. In order to investigate this in the GFIT test, data from near-field microphones are analyzed with flow over the grooves and the acoustic drivers off.

\section{A. Analysis}

Cavity noise simulations and experiments have investigated the mechanisms driving resonances from flow over cavities. Rossiter [11] identified two types of unsteady oscillations in cavities; oscillations from unsteady separation dominate in shallow cavities $(L / D>4)$, and acoustic cavity resonances dominate for deep cavities $(L / D<4)$. Block [12] denoted these oscillations as lengthwise and depthwise, and found tones were concentrated around frequencies where these two mode types intersected. The lengthwise oscillations are formed when flow vortices in the shear layer from upstream edge of the cavity impact the downstream edge of the cavity. The sound waves generated from this impact travel upstream where they induce vertical motion in the shear layer driving a feedback loop. The expected frequencies associated with the lengthwise oscillations were found to be related to the flow Mach number $(M)$, the real part of the axial wavenumber of the disturbance traveling downstream, and the cavity length-to-diameter ratio $(L / D)$. The mode number $(n)$ denotes the number of oscillations in the cavity length. The expected frequency for lengthwise oscillations provided by Block [12] is shown below in Eq. 9

$$
f_{L}=\frac{U_{\infty}}{L} \frac{n}{\frac{1}{0.57}+M\left(1+\frac{0.514}{L / D}\right)}
$$

Depthwise modes are acoustic cavity modes that are insensitive to flow Mach number and scale with the depth of the cavity. The expected frequency for the depthwise mode given by Block [12] is shown below in Eq. 10.

$$
f_{D}=\frac{U_{\infty}}{L} \frac{0.25}{1+0.65\left(\frac{L}{D}\right)^{0.75}}
$$

\section{B. Experiment Summary}

In order to evaluate the noise generated from flow over the 2 inch wide grooves, time-series data were acquired from 13 microphones nearest the treatment as shown in Fig. 11. The time-series data were acquired at a $25.6 \mathrm{kHz}$ sample rate and processed to narrowband Sound Pressure Level (SPL) spectra with a $2^{14}$ samples per window resulting in a frequency bin width of $1.6 \mathrm{~Hz}$. The geometric directivity angles (flow direction is $\theta=180^{\circ}$ ) are utilized to compute emission angles $\left(\theta_{e}\right)$ as shown below to determine source directivity [13, 14].

$$
\theta_{e}=\theta_{g}-\arcsin \left(M \sin \left(\theta_{g}\right)\right)
$$

The Mach numbers presented in this section are the Mach number over the lined section of the GFIT duct. Data were acquired for each of the groove configurations shown in Fig. 5 to investigate the sources of groove/cavity noise and for the four treated configurations shown in Fig. 4 to evaluate the effect of acoustic liners on groove noise.

\section{Results}

The source of cavity noise from flow over a series of grooves is investigated by comparing spectra with a varying number of cavities exposed to the flow. Figure 12 shows the resulting spectra measured at the upstream near-field microphone $\left(\theta_{g}=40^{\circ}\right)$ from Mach 0.2 to 0.44 . The predicted frequencies for lengthwise (Eq. 9) and depthwise (Eq. 10) oscillations are plotted as blue and black dashed lines. While the series of grooves provides many combinations of forward and backward facing steps, the assumed length of 1.75 inches for the lengthwise mode calculation is the total length for a series of 5 grooves. As found by Block [12], the dominant tone is found around the intersection of lengthwise and depthwise modes. The dominant tone was measured to be in excess of $150 \mathrm{~dB}$ SPL at Mach 0.44. While a single groove did not generate much more noise than the hard-wall noise levels, the inclusion of more grooves in series produced increasingly louder tones.

The tone directivity, as shown in Fig. 13 is evaluated by plotting the tone amplitude as a function of emission angle $\left(\theta_{e}\right)$ computed for each of the microphones circled in Fig. 11. It is assumed that the measurements are in the near-field 


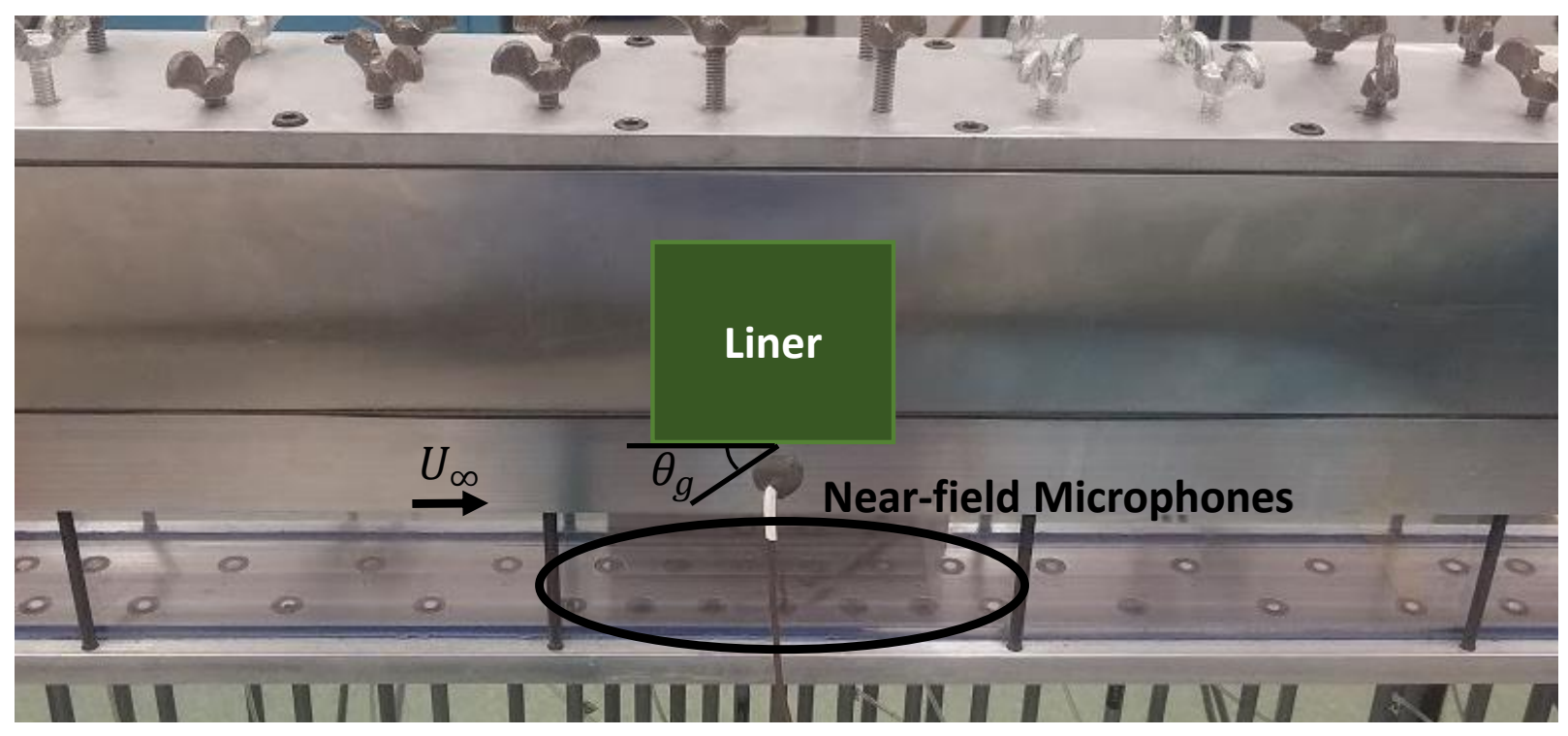

Fig. 11 Near-field microphones used for the investigation of groove noise.

and therefore, the directivity can be evaluated before the sound coalesces into duct modes. At each grazing flow Mach number, the dominant tone frequency was identified. Noise generated from lengthwise cavity modes is expected to propagate upstream [11, 12], while noise from a depthwise cavity mode propagates at $\theta_{e}=90^{\circ}$ [15]. In Fig. [13, the dominant tone propagates upstream in all cases except at Mach 0.37, which is around the expected intersection of the lengthwise and depthwise modes. The cavity tone frequencies align with the frequencies where additional noise was present in the W-8 results [5] suggesting the source of additional noise from circumferential grooves may be due to cavity resonances. While these results show large hay-stacked tones, the noise penalty measured in W-8 appeared to be more broadband. This is believed to be due to the interaction of the fan blade sweeping over the grooves.

In order to evaluate the impact of acoustic treatments installed at the bottom of the grooves, spectra are plotted from an upstream $\left(\theta_{g}=40^{\circ}\right)$ near-field microphone for each flow Mach in Fig. 14. The inclusion of the acoustic treatments reduced the amplitudes by up to $10 \mathrm{~dB}$ SPL and increased the resonance frequencies of the cavity resonance by up to $10 \%$. The liner impedance at the bottom of the grooves has the ability to absorb some of the flow oscillations and alter the resonance feedback path. When installed over a turbofan rotor [5], these liners similarly reduced the noise generated by flow over grooves. Over-the-rotor, this noise source is likely mitigated at higher fan speeds when the blade passing impedes the feedback path required for a cavity resonance. 
(a) $\mathrm{M}=0.19$

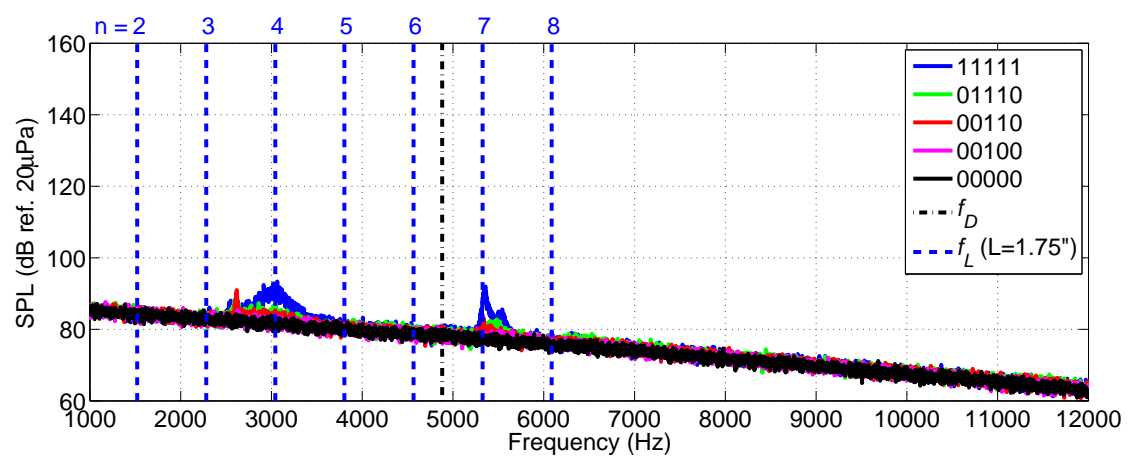

(b) $\mathrm{M}=0.28$

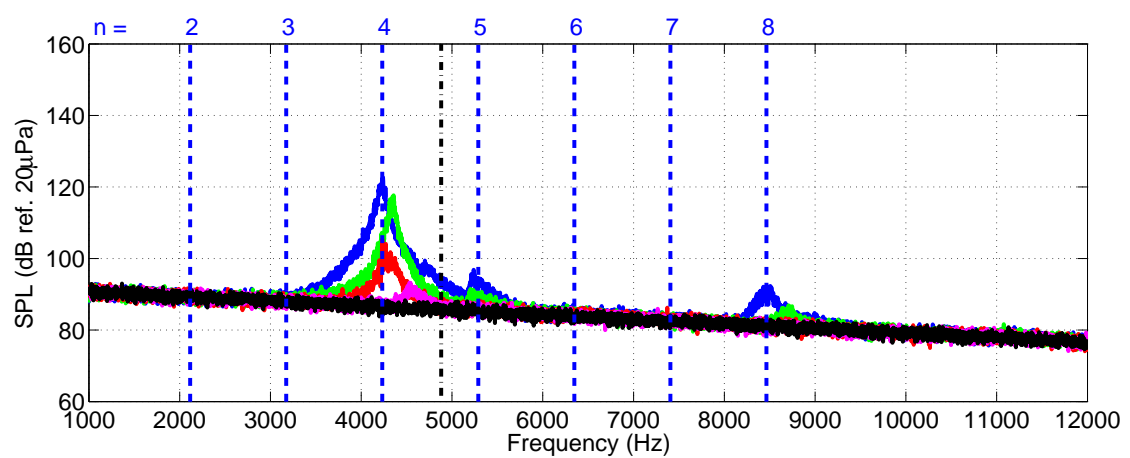

(c) $\mathrm{M}=0.37$

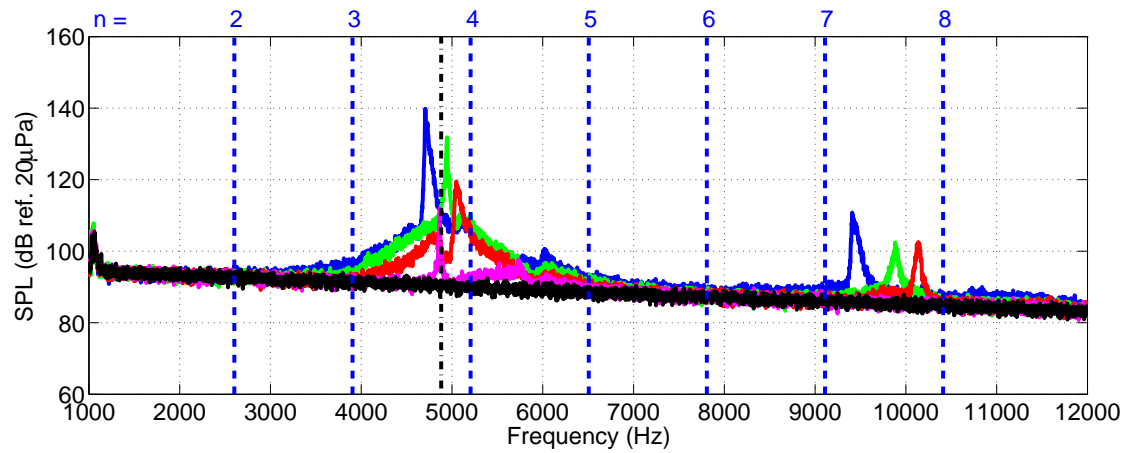

(d) $\mathrm{M}=0.44$

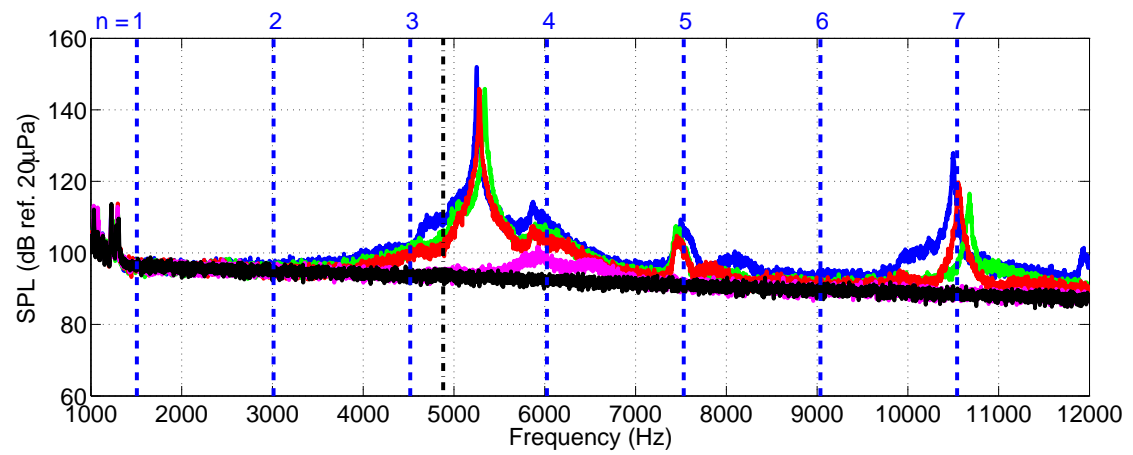

Fig. 12 Sound Pressure Level (SPL) spectra from flow over a series of grooves/cavities with increasing grazing flow Mach number measured at $\theta_{g}=40^{\circ}$ with predicted cavity resonance frequencies identified. 


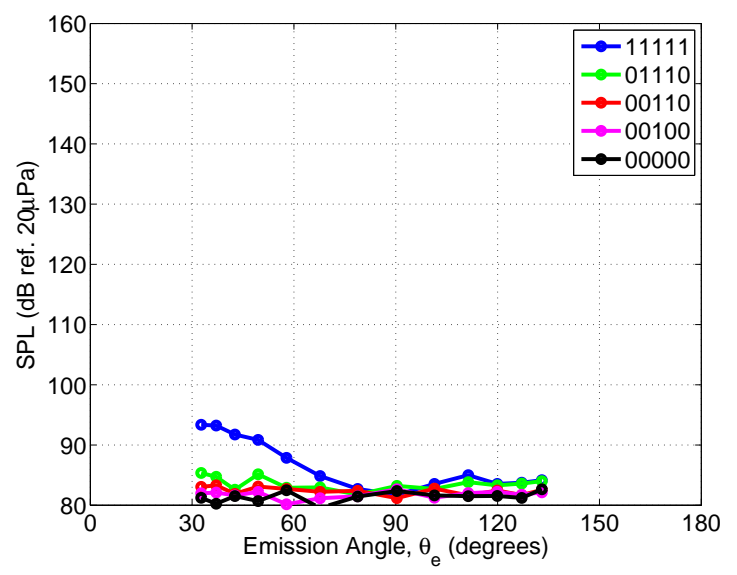

(a) $M=0.19, f \approx 3000 \mathrm{~Hz}$

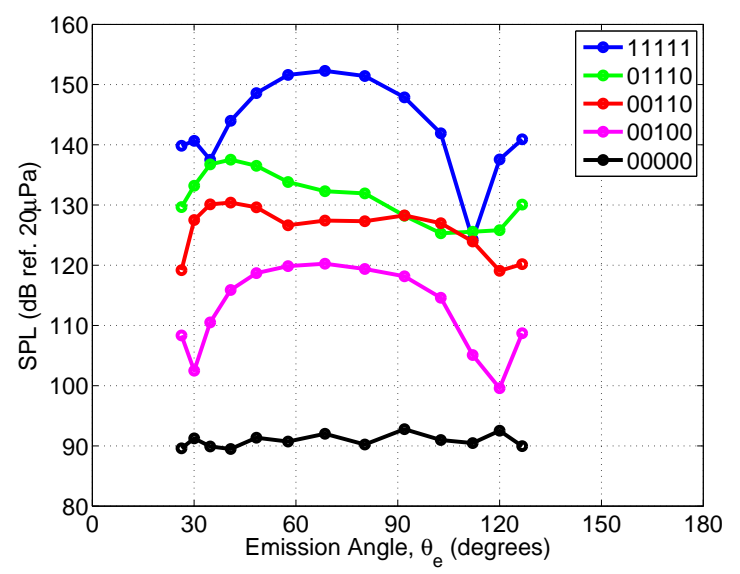

(c) $M=0.37, f \approx 4900 \mathrm{~Hz}$

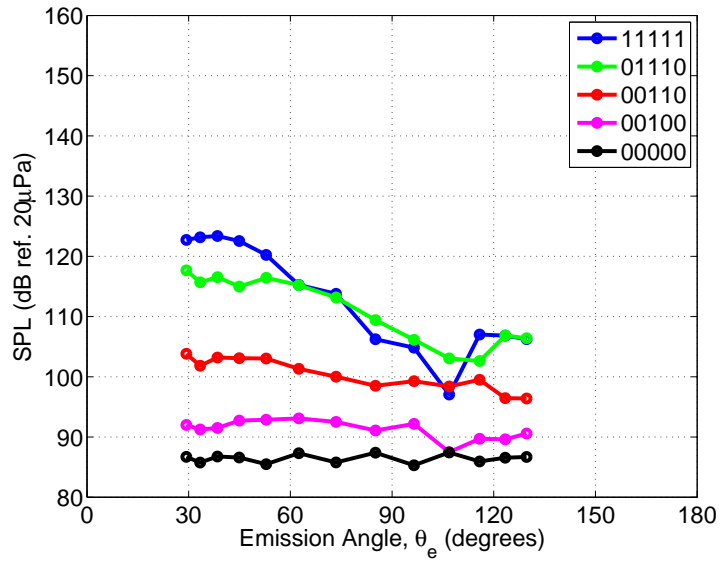

(b) $M=0.28, f \approx 4200 \mathrm{~Hz}$

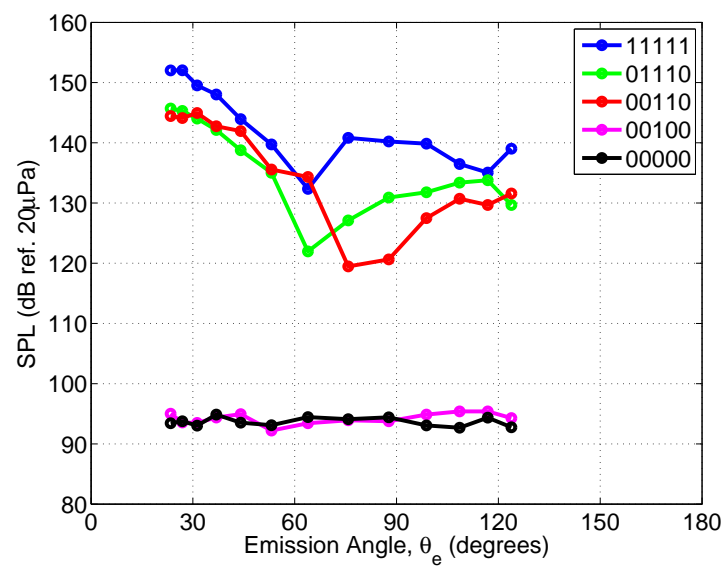

(d) $M=0.44, f \approx 5200 \mathrm{~Hz}$

Fig. 13 Directivity of the dominant tone at each Mach number. *Assumes measurements are near enough to evaluate source directivity. 
(a) $\mathrm{M}=0.19$

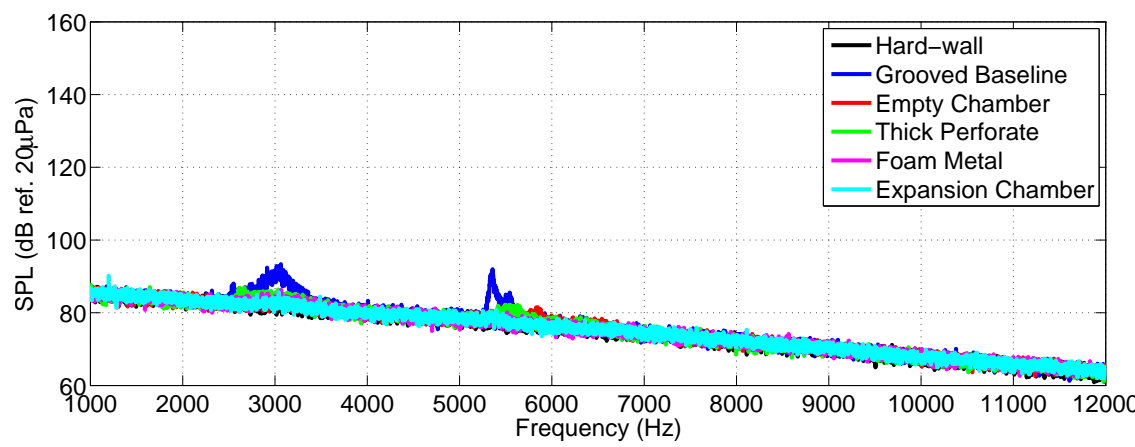

(b) $\mathrm{M}=0.28$

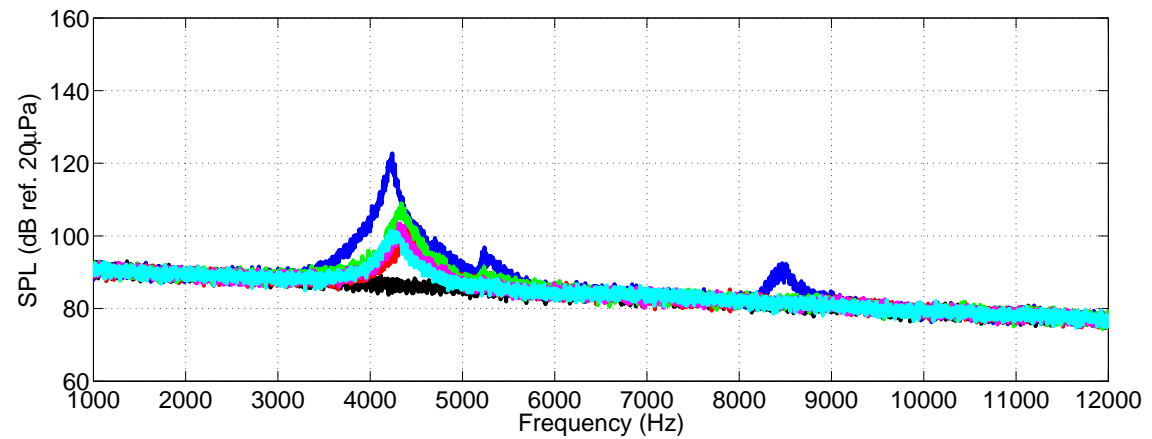

(c) $\mathrm{M}=0.37$

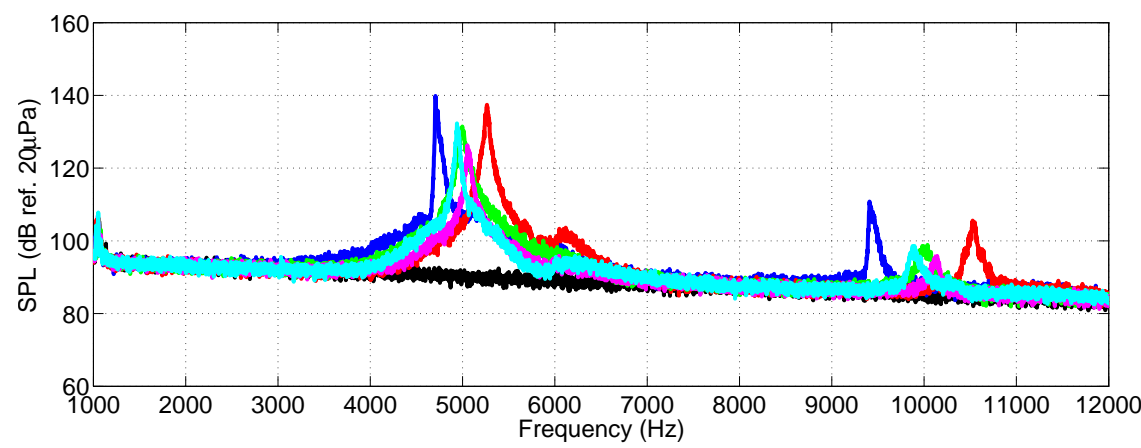

(d) $\mathrm{M}=0.44$

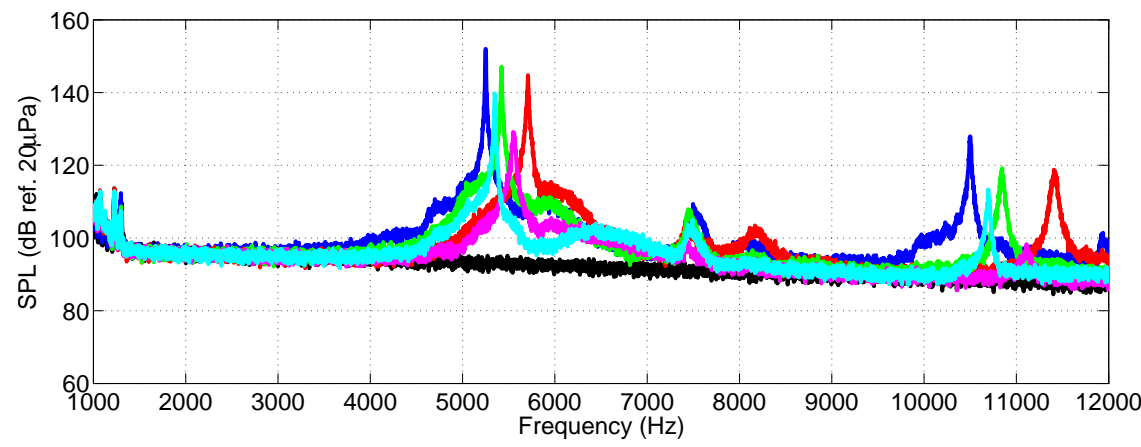

Fig. 14 Effect of acoustic liners on cavity noise measured at $\theta_{g}=40^{\circ}$ for each grazing flow Mach number. 


\section{Conclusions}

Testing of over-the-rotor acoustic casing treatments was completed in the Grazing Flow Impedance Tube at NASA Langley Research Center. Data were acquired to understand the scaling of acoustic liner absorption with grazing flow and to investigate the noise created from flow over a series of grooves.

Two inch long acoustic treatment samples were found to provide as much as $14 \mathrm{~dB}$ plane wave absorption. For all treatments tested, as the grazing flow Mach number increased, the absorption curves broadened and the frequency of peak absorption decreased. While the peak absorption coefficient increases with increasing flow Mach number, two of the liners tested showed a decreasing insertion loss due to a reducing reflection coefficient. Insertion loss curves were fit with a polynomial to help quantify and correlate the effect of flow on these acoustic liners. The polynomial fit factors can be used to aid the design of turbofan liners.

Flow over grooves was found to generate cavity resonances in the same frequency range measured when the grooves were installed over a turbofan rotor [5]. The cavity resonances appear most dominant at the intersection of lengthwise and depthwise cavity modes, as was previously shown by Block [12]. These resonances generated tones as loud as $152 \mathrm{~dB}$ SPL. The noise increase over a turbofan rotor appeared more broadband, likely due to the interaction of this flow oscillation with the passing blade tips. The inclusion of acoustic liners installed below the bottom of the grooves were found to reduce the amplitude (by up to $10 \mathrm{~dB}$ ) and alter the frequency (by up to 10\%) of the cavity resonance. This noise reduction due to the acoustic liners is similar to what was seen when installed over a turbofan rotor. Over the rotor, this noise source was eliminated at higher fan speeds when the blade passes frequently enough to impede the feedback path required for a cavity resonance.

The experiments conducted further the understanding of the effects associated with circumferentially grooved over-the-rotor acoustic treatments by quantifying the impact of grazing flow on liner characteristics and identifying the source of a potential noise penalty.

\section{Acknowledgments}

The authors would like to thank Mr. Alonzo M. Reid for his efforts supporting this test. This work was supported by the Advanced Air Transport Technology Project of the NASA Advanced Air Vehicles Program.

\section{References}

[1] Thomas, R. H., Burley, C. L., and Nickol, C. L., "Assessment of the Noise Reduction Potential of Advanced Subsonic Transport Concepts for NASA's Environmentally Responsible Aviation Project," 54th AIAA Aerospace Sciences Meeting, AIAA SciTech Forum, American Institute of Aeronautics and Astronautics, 2016. doi:10.2514/6.2016-0863, URL https: //doi.org/10.2514/6.2016-0863

[2] Sutliff, D. L., Jones, M. G., and Hartley, T. C., "High-Speed Turbofan Noise Reduction Using Foam-Metal Liner Over-the-Rotor," Journal of Aircraft, Vol. 50, No. 5, 2013, pp. 1491-1503. doi:10.2514/1.c032021, URL https://doi.org/10.2514/1. CQ32021

[3] Hughes, C., and Gazzaniga, J., "Effect of Two Advanced Noise Reduction Technologies on the Aerodynamic Performance of an Ultra High Bypass Ratio Fan,” No. AIAA-2009-3139 in Aeroacoustics Conferences, American Institute of Aeronautics and Astronautics, 2009. doi:10.2514/6.2009-3139, URL https://doi .org/10.2514/6.2009-3139

[4] Bozak, R., Hughes, C., and Buckley, J., "The Aerodynamic Performance of an Over-the-Rotor Liner With Circumferential Grooves on a High Bypass Ratio Turbofan Rotor," GT2013-95114, 2013. doi:10.1115/gt2013-95114, URL http://dx . doi. org/10.1115/GT2013-95114

[5] Bozak, R., and Dougherty, R. P., "Measurement of Noise Reduction from Acoustic Casing Treatments Installed Over a Subscale High Bypass Ratio Turbofan Rotor," 2018 AIAA/CEAS Aeroacoustics Conference, AIAA AVIATION Forum, American Institute of Aeronautics and Astronautics, 2018. doi:10.2514/6.2018-4099, URL https://doi .org/10.2514/6.2018-4099

[6] Elliott, D., Woodward, R., and Podboy, G., "Acoustic Performance of Novel Fan Noise Reduction Technologies for a High Bypass Model Turbofan at Simulated Flight Conditions," 15th AIAA/CEAS Aeroacoustics Conference (30th AIAA Aeroacoustics Conference), No. AIAA-2009-3140 in Aeroacoustics Conferences, American Institute of Aeronautics and Astronautics, 2009. doi:10.2514/6.2009-3140, URL https://doi.org/10.2514/6.2009-3140

[7] Gazella, M., Takakura, T., Sutliff, D. L., Bozak, R., and Tester, B. J., "Evaluating the Acoustic Benefits of Over-the-Rotor Acoustic Treatments Installed on the Advanced Noise Control Fan," No. AIAA-2017-3872 in AIAA AVIATION Forum, American Institute of Aeronautics and Astronautics, 2017. doi:10.2514/6.2017-3872, URL https://doi .org/10.2514/6.2017-3872 
[8] Bozak, R. F., and Podboy, G. G., "Evaluating the Aerodynamic Impact of Circumferentially Grooved Fan Casing Treatments with Integrated Acoustic Liners on a Turbofan Rotor," 2019.

[9] Brown, M., Jones, M., and Watson, W., "Uncertainty Analysis of the Grazing Flow Impedance Tube," 18th AIAA/CEAS Aeroacoustics Conference (33rd AIAA Aeroacoustics Conference), Aeroacoustics Conferences, American Institute of Aeronautics and Astronautics, 2012. doi:10.2514/6.2012-2296, URL https://doi .org/10.2514/6.2012-2296

[10] Pierce, A. D., Acoustics : An Introduction to Its Physical Principles and Applications, Acoustical Society of America, Woodbury, N.Y, 1989.

[11] Rossiter, J. E., "Wind-Tunnel Experiments on the Flow over Rectangular Cavities at Subsonic and Transonic Speeds," Ministry of Aviation, Reports, and Memoranda, Vol., No. 3438, 1964, p. . URL http://naca.central.cranfield.ac.uk/reports/ $\mathrm{arc} / \mathrm{rm} / 3438 . \mathrm{pdf}$

[12] Block, P. J. W., "Noise Response of Cavities at Varying Dimensions at Subsonic Speeds," NASA TN D-8351, NASA, 1976. URL https://ntrs.nasa.gov/archive/nasa/casi.ntrs.nasa.gov/19770007874.pdf

[13] Brown, C. A., and Stephens, D. B., “Acoustic Methods Used in the NASA Glenn 9- by 15-Foot Low-Speed Wind Tunnel,” NASA TM-2018-218874, 2018. URL https://ntrs.nasa.gov/archive/nasa/casi.ntrs.nasa.gov/20180004163.pdf

[14] Mueller, T. J. (ed.), Aeroacoustic Measurements, Springer, 2002.

[15] Ahuja, K. K., and Mendoza, J., "Effects of Cavity Dimensions, Boundary Layer, and Temperature on Cavity Noise With Emphasis on Benchmark Data to Validate Computational Aeroacoustics Codes," NASA CR-4653, NASA, 1995. URL https://ntrs.nasa.gov/archive/nasa/casi.ntrs.nasa.gov/19950018459.pdf 